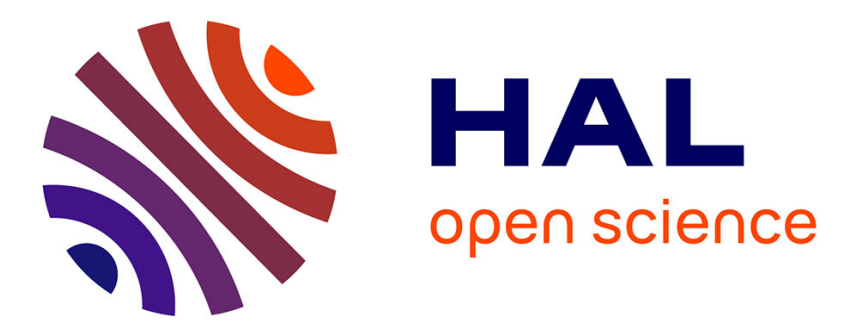

\title{
Computational fatigue assessment of mooring chains under tension loading
}

Imanol Martinez Perez, Andrei Constantinescu, Philippe Bastid, Yan-Hui

Zhang, Vengatesan Venugopal

\section{To cite this version:}

Imanol Martinez Perez, Andrei Constantinescu, Philippe Bastid, Yan-Hui Zhang, Vengatesan Venugopal. Computational fatigue assessment of mooring chains under tension loading. Engineering Failure Analysis, 2019, 106, 10.1016/j.engfailanal.2019.06.073 . hal-02411493

\section{HAL Id: hal-02411493 \\ https://hal.science/hal-02411493}

Submitted on 5 May 2020

HAL is a multi-disciplinary open access archive for the deposit and dissemination of scientific research documents, whether they are published or not. The documents may come from teaching and research institutions in France or abroad, or from public or private research centers.
L'archive ouverte pluridisciplinaire HAL, est destinée au dépôt et à la diffusion de documents scientifiques de niveau recherche, publiés ou non, émanant des établissements d'enseignement et de recherche français ou étrangers, des laboratoires publics ou privés. 


\title{
Computational fatigue assessment of mooring chains under tension loading
}

\author{
Imanol Martinez Perez ${ }^{\mathrm{a}, *}$, Andrei Constantinescu ${ }^{\mathrm{b}}$, Philippe Bastid ${ }^{\mathrm{c}}$, Yan-Hui Zhang ${ }^{\mathrm{c}}$, \\ Vengatesan Venugopal ${ }^{\mathrm{a}}$
}

${ }^{a}$ Institute for Energy Systems, School of Engineering, The University of Edinburgh, King's Buildings, Edinburgh EH9 3JL, UK

${ }^{\mathrm{b}}$ Laboratoire de Mécanique des Solides (LMS), CNRS UMR 7649, Ecole Polytechnique 91128, Palaiseau Cedex, France

${ }^{\mathrm{c}}$ TWI Ltd, Granta Park, Cambridge CB21 6AL, UK

This paper presents a computational fatigue assessment method of mooring chains under tensile loading, it is composed of a mechanical analysis followed by a fatigue analysis. The mechanical analysis is performed in two steps: residual stress prediction and service loading. From this analysis, the shakedown cycle is extracted at the critical points, ie: the asymptotically stabilized stress-strain cycles. As the mooring chain under service loading is under elastic shakedown, the Dang Van fatigue criterion is applied for the fatigue analysis. The accuracy of the proposed fatigue assessment method is proved by comparing with the experimental results from full-scale fatigue testing of mooring chain in seawater. The numerical results match both the experimental observations with respect to the localization of the damage zone and the lifetime.

\section{Introduction}

Mooring system are designed to keep dynamically floating structures on a fixed geographical position within a specified tolerance. Mooring systems have been traditionally used by the Oil and Gas industry for production units (FPSO) and have recently found application in the Offshore Renewable Energy Industry, as for example in mooring floating wind turbines. For both industries, the failure of the mooring system can give rise to large accidents with devastating economic losses as well as dramatic environmental consequences. Mooring systems are generally composed of a series of lines each of them composed of 3 sections: chain links in the upper (at the interface with the vessel) and bottom sections (sea bed touch down area) and polyester or wire rope in the central section.

During the last decade, the increasing number of mooring incidents has risen a concern among Oil and Gas companies. The following graph (Fig. 1) reveals an upwards trend of the number of failures or pre-emptive mooring line replacements between 1997 and 2013. This graph displays data gathered from a survey among Oil and Gas companies conducted by Fontaine et al. [1]. Confirming this trend, Kvitrud [2] reported 15 failures of offshore mooring lines in the Norwegian North Sea between 2011 and 2013. More details of some of these failures can be found in [1-4].

Several authors [1-6] have identified fatigue at the origin of various incidents and accidents that resulted in the failure of the chain links. They reported that statistically, fatigue is the most frequent failure mechanism, followed by overload and damage during installation. Consequently, understanding the factors governing fatigue behaviour and developing efficient and robust fatigue assessment methods represents a challenge for industry. Within service loading, two particular loading configurations have been

\footnotetext{
* Corresponding author.

E-mail address: i.martinez-perez@ed.ac.uk (I. Martinez Perez).
} 


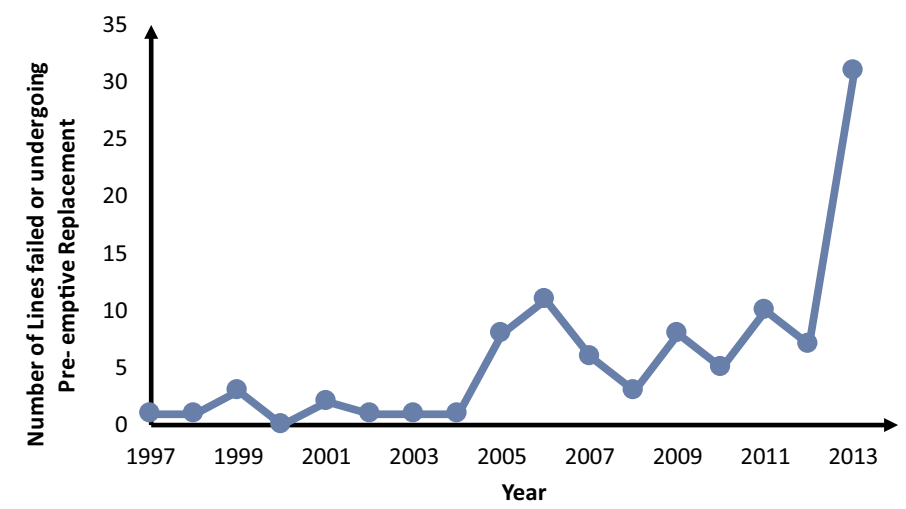

Fig. 1. Number of mooring legs failed or pre-empltuy during a five year period. Data from [1].

identified and are actually accepted as standard fatigue failure modes: Tensile loading and Out-of-Plane Bending (OPB).

In the last two decades, an important effort has been made for the understanding of the failure of mooring chains due to fatigue. Some of the projects, both JIP (Joint Industry Projects) and academic, in this direction focus on: understanding Out-of-Plane Bending [7-9], studying corrosion and its effect on fatigue life [10-12], assessing the remaining life of used chains [13], deriving S-N curves of mooring chains accounting for corrosion [14], obtaining fatigue properties of mooring chain steel [15-17], quantifying residual stresses and their impact on fatigue life [18-20] or provide guidance for underwater inspection and monitoring [5,21].

Let us provide a brief description of both fatigue failure modes. Out-of-Plane Bending of chain links was considered as the main cause of the Girassol incident, as first identified by Jean et al. [8]. It was a premature failure of several chain links of the mooring line of the loading buoy. The rupture occurred eight months after the installation and was not predicted by industry standards. Therefore, this loading mode attracted the attention of several research programs and multiple publications can be found in the literature, see for example [7,9,22-27]. Among this effort in understanding and quantifying Out-of-Plane Bending, it is worth mentioning a Joint Industry Program (JIP) gathering 28 different companies whose objectives were a better understanding of Out-of-Plane Bending fatigue and propose fatigue design recommendations, their main findings can be found in [7,9]. When this project concluded, Bureau Veritas issued a guidance note with recommendations for better assessing the damaging effect of Out-of-Plane Bending [22]. However, these results still do not provide a robust design and fatigue assessment method for this loading mode, they provide parametric formulas and Stress Concentration Factors to estimate the stresses at the critical locations. Moreover, a drawback of their work is how they predicted residual stresses. They did not account for all the stages of the manufacturing process that generate residual stresses. This simplification can have a significant effect in the estimated lifetime, as already demonstrated by Martinez et al. [28].

Tensile Loading is the nominal loading mode. Current Standards (API-RP-2SK [29] and DNV-OS-E301 [30]) base the fatigue assessment on S-N curves derived experimentally, without specifying the mean load for which they have been obtained and neglecting the effect of the mean load. Nevertheless, recently it has been pointed out that mean load should be incorporated in the fatigue assessment of mooring chains under tensile loading [13].

In spite of the research effort done in the last decade, we still do not dispose of a robust and comprehensive fatigue design method for the lifetime prediction of mooring chains under both loadings. The design method must include the combine effect of mean load and residual stresses. The latter should be measured experimentally or predicted accounting for all the relevant manufacturing stages, and not only the last one.

In this paper, we shall show that one can define a computational design method for assessing the lifetime of mooring chains taking into account essential features both of the manufacturing process and the multiaxiality of the load path in the stress space. From the manufacturing process we have modelled heat treatment and proof loading, which has permitted and accurate estimation of the residual stress field in the chain. Both the residual stress state and the multiaxiality of the loading cycle are taken into account by Dang Van fatigue criterion [31,32]. Similar problem settings have already been proposed in the past for the fatigue life prediction of rail tracks [33]or crankshafts [34], in both problems residual stresses have a non-negligible influence in the fatigue lifetime. The originality of the present study lies essentially in adapting and interpreting classical notions, models and techniques in order to obtain a reliable fatigue prediction for mooring chains. The discussion presented next is dedicated to Tensile loading of the mooring chains. However, the generality of the proposed method permits a similar analysis of other loading conditions, such as Out-of-Plane Bending, as well as the extension to variable loading using a stress-resistance approach [35-37].

This paper proposes a computational fatigue assessment methodology of mooring chains under tension loading accounting for residual stresses. They were predicted studying all the stages of the manufacturing process. In a computational method, as commonly practised in the industry [38], one can distinguish two steps:

(i) A mechanical analysis based on the knowledge of the geometry, the constitutive law, the boundary conditions, the manufacturing process and the service loading, which will provide the cyclic response of the structure in terms of strain and stress.

(ii) A fatigue analysis based on the study of the stress-strain response computed before in each geometric point of the structure and the assessment of the local elastic or plastic shakedown state or a ratcheting state and the application of an appropriate lifetime criterion. 


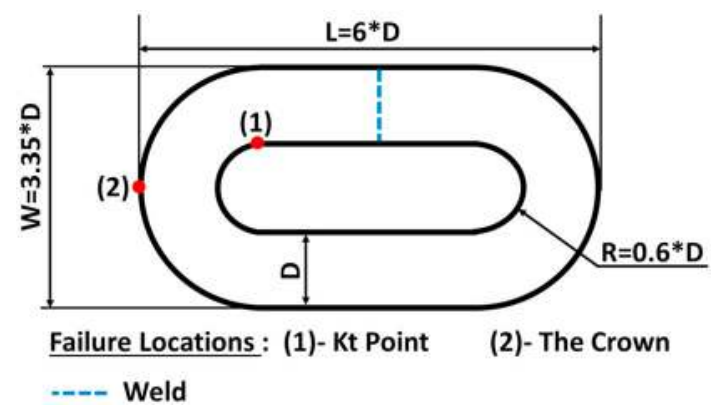

Fig. 2. Nominal dimensions of a chain link and fatigue failure locations under tensile loading.

An example of a complete approach can be found in [39]. The mechanical analysis has shown that the stabilized cycle of mooring chains under tensile loading is of an elastic shakedown. Consequently, the Dang Van Fatigue Criterion [40] has been chosen for the fatigue analysis.

This paper starts with an overview of mooring chains, i.e. geometry, material, service loading and its manufacturing stages. The second section presents the mechanical analysis: residual stress prediction followed by service loading. Two different FEA (Finite Element Analysis) models are described: Heat treatment model (which simulates the heat treatment of chain links during the manufacturing process) and Tensile loading model. The third section reports the fatigue analysis implementing Dang Van fatigue criterion. The last section compares the fatigue lifetimes derived previously with fatigue tests performed at TWI Ltd. as part of a Joint Industry Program.

\section{Mooring chain: structure and material}

A mooring chain is composed of a series of interconnected links (see Fig. 2) which transmit the applied load from one link to the next by direct contact. Mooring chains are manufactured out of hot rolled low alloy carbon steel. Engineering Standards (DNV-OSE302 [41] and IACS W22 [42]) define different grades of mooring chain steel. The difference between each grade relates to the required mechanical properties. The newest material grades are R6 and R5S [43], although previous material grades, R5 and R4 are still widely used today. In addition, no chain made of R5S or R6 is yet in service today. Mooring chain steels have high yield strength compared to other low alloy carbon steels. Table 1 reports the mechanical properties for both steel grades measured by different authors and the minimum values required by the Standard DNV-OS-E302 [41]:

The main steps in the manufacturing process or mooring chain links are (i) cutting of the length of the chain link out of a bar, (ii) hot bending, (iii) flash butt welding of the extremities, (iv) heat treatment and (v) proof loading. We shall focus in the last two operations, because as it will explained in the following section, they are the only ones relevant from a residual stress point of view. The heat treatment stage is composed by double quenching in water, tempering and cooling in water. The temperatures of the first and second quench are $920^{\circ} \mathrm{C}$ and $880^{\circ} \mathrm{C}$ respectively $[16,17]$. The resulting microstructure from heat treatment is fine grain tempered martensite and bainite [15-17]. As a final operation before being putted into service, chains links must undergo a mandatory proof load to check their strength and fitness for service, the value of the Proof load is established by the Standards [41,42] and is specified to be about $70 \%$ of the static breaking load. For each of these steps, residual stresses are generated due to nonhomogenous strains and/or thermal gradients. The resultant residual stress field will be the superposition of residual stresses from heat treatment and proof loading.

The nominal dimensions of the chain are given as a function of the diameter [42], as reported in Fig. 2. This figure also illustrates the fatigue failure locations of chains under tension loading [13,20,44,45]. At both locations Stress Concentration Factor (defined as the ratio between the maximal principal stress and the nominal stress; the latter computed dividing the total external force applied at the chain by its cross section) take high values, approximatively a value of 4 [44].

One chain size has been considered in this study, a $127 \mathrm{~mm}$ diameter. The Minimum Breaking Load (MBL) is the minimum load that a chain segment of at least 3 chain links must withstand during $30 \mathrm{~s}$ without fracture [42], it is defined as a function of the material grade and the diameter of the chain. The imposed fatigue loading will be referred as a percentage of the Minimum Breaking Load (MBL). Table 2 presents the values of Proof Load and Minimum Breaking Load for the diameter (127 mm) and material grades studied in this paper.

Table 1

Mechanical properties of mooring chain steel from the literature and minimum values required by engineering standard DNV-OS-E302 [41].

\begin{tabular}{lllllll}
\hline Material grade & $\sigma_{0.2 \%}{ }^{Y}[\mathrm{MPa}]$ & $\sigma^{U}[\mathrm{MPa}]$ & Source & $\sigma_{\min }{ }^{Y}[\mathrm{MPa}]$ & $\sigma_{\min }{ }^{U}[\mathrm{MPa}]$ & 860 \\
\hline R4 & 896 & 959 & {$[9]$} & 580 & 12 \\
& 880 & 1000 & {$[20]$} & & \\
R5 & 970 & 1018 & {$[17]$} & 700 & 1000 \\
& 1000 & 1100 & {$[20]$} & & 12 \\
\hline
\end{tabular}


Table 2

Minimum breaking load and proof load for a $127 \mathrm{~mm}$ chain. Source DNV-OS-E302 [41].

\begin{tabular}{lllll}
\hline Diameter $(\mathrm{mm})$ & Material grade & Proof load $(\mathrm{kN})$ & Minimum breaking load $(\mathrm{MBL})(\mathrm{kN})$ & Nominal stress under MBL(MPa) \\
\hline \multirow{2}{*}{127} & R4 & 10,479 & 14,955 & 590.3 \\
& R5 & 12,171 & 17,466 & 689.4 \\
\hline
\end{tabular}

\section{Mechanical analysis}

As specified in the introduction, the first part of the computational design methods is the mechanical analysis. The first operation within this part is the simplified modelling of the manufacturing process to predict residual stresses, after, service loading is applied to derive the stabilized stress cycle. Two different FEA models have been employed:

(i) Heat treatment model: Simulates heat treatment

(ii) Tensile loading model: Simulates Proof load and Service loading.

Both of them have been computed using ABAQUS 6.14 and have the same geometry: two chain links accounting for one symmetry plane. Nevertheless, they have different constitutive laws, the main characteristic of Heat treatment model is that it uses temperature dependant material parameters, while Tensile loading model accounts for combined nonlinear hardening. This section is divided as follows, first the modelling of the residual stress field remaining after manufacturing is described. Second, the FEA models are presented. Third, the predicted residual stress field after heat treatment and the end of the manufacturing process is presented. Finally, the stabilized response of the chain when subjected to service loading is illustrated.

\subsection{Manufacturing residual stress prediction}

Different models for predicting residual stresses in mooring chains can be found in the literature, to mention a few [18,20,46]. All these models only considered proof load as source of residual stresses. They assumed that after heat treatment mooring chain links were residual stress free, however it is widely accepted that in quenched cylinders heat treatment leaves considerable compressive residual stresses at the surface and tensile at the core [47-50]. In addition, tempering partially relaxes the residual stress distribution left by quenching. In order to overcome this, Martinez Perez et al. [28] presented a model that accounted for both heat treatment and proof loading as sources of residual stresses. This model has been used in this study.

As described before, mooring chain manufacturing involves several steps during which residual stresses are generated due to nonhomogenous strains and/or thermal gradients. The initial temperature of the second quench is above the temperature at which austenite stops forming (Ac3), it can be assumed that the residual stresses created in the previous stages (hot bending of the chain, welding and first quench) are relaxed. Consequently, only the last stages of the manufacturing process, second heat quench, tempering and proof loading have been modelled:

- Step 1: Quenching. Starting at the quenching temperature, the chain is cooled down in water. The water bath is continually refrigerated; therefore, the temperature of the water has been considered to be constant.

- Step 2: Tempering. The chain is heated until tempering temperature is reached.

- Step 3: Water Cooling. The chain is cooled down in water until room temperature.

- Step 4: Proof Load. The value of the Proof Load depends of the material grade and the chain diameter, it has been indicated in Table 2.

- Step 5: Unload. Proof load is removed and residual stresses from heat treatment and Proof load remain in the chain.

Residual stress prediction has been subdivided in two models, heat treatment (Steps 1, 2, 3) simulated by Heat treatment model and proof loading (Steps 4,5) simulated by Tensile loading model.

\subsection{Heat treatment model (steps 1, 2,3)}

Quenching and tempering are multiphysics processes where the temperature field, the microstructure and the stress/strain field interact between each other in a complex manner. Heat transfer is the main physical process which drives heat treatment by triggering phase transformation and the formation of thermal stress/strains. In the model presented in this paper, no phase transformations have been taken into account. By neglecting phase transformations, the computational cost of the fatigue assessment is kept under a reasonable level. The validity of this assumption was checked qualitatively against residual stress measurements on small quenched cylinders, more information can be found in [28]. The assumption that the thermal problem is uncoupled from the mechanical problem has been made, the contribution of inelastic dissipation to heating and heat transfer by means of conduction in the contact zone between chain links have been neglected. No contact interaction has been considered in this model. This model has two different analyses:

First, a Heat Transfer analysis is run for obtaining the thermal profile. During the first and third step, the interaction between the chain and water is complex. When the chain is immersed the following process is triggered. First, a water blanket appears, then 
nucleate boiling takes place and finally convective cooling occurs. In order to account for this mechanisms, a temperature dependent heat transfer coefficient taken from the literature [50] has been used.

Second, the obtained thermal profile was exported to a Stress analysis for predicting the resultant residual stress field. The mechanical fields are defined by an elastoplastic constitutive law under the hypothesis of small strains and the equilibrium equation:

$$
\operatorname{div} \sigma=0
$$

The mechanical field is defined as follows:

$$
\begin{aligned}
& \sigma=\mathrm{C}\left(\varepsilon-\varepsilon_{p}-\varepsilon_{t h}\right) \\
& \dot{\varepsilon}=\gamma \nabla f\left(A_{p}\right)
\end{aligned}
$$

where $\varepsilon_{t h}$ and $\varepsilon_{p}$ are the plastic and thermal strain tensors respectively, C is the fourth order elasticity tensor (defined by the Young moduli and the Poisson ratio). The values of $\gamma$ and $A_{p}$ are defined by a von Mises equivalent stress yield criterion and the assumption of isotropic hardening behaviour:

$$
\begin{aligned}
& A_{p}=\operatorname{dev} \sigma \\
& \gamma=\sqrt{\frac{3}{2}}\left\langle J_{2}\left(A_{p}\right)\right\rangle
\end{aligned}
$$

where $J_{2}\left(A_{p}\right)$ is the second invariant of the deviatoric stress tensor.

The model has two temperature dependent parameters, the Young moduli (E)and the yield limit, which are presented in Fig. 3, more information can be found in [28].

\subsection{Tensile loading model: proof loading (steps 4,5) and service loading}

This model predicts the final residual stresses field after Proof load and the stabilized stress cycle when service loading is applied. The predicted residual stress field from the heat treatment stage is incorporated as an initial state before Proof loading analysis. The material behaviour was modelled as elastic-plastic with combined non-linear isotropic and non-linear kinematic hardening. The yield surface is given by von Mises equivalent stress yield criterion:

$$
F=f(\sigma-\alpha)-\sigma^{0}
$$

The isotropic hardening is given by:

$$
\sigma^{0}=\left.\sigma\right|_{0}+Q_{\infty}\left[1-\exp \left(-b \bar{\varepsilon}_{p}\right)\right]
$$

where $\sigma^{0}$ is the flow stress, $\left.\sigma\right|_{0}$ is the initial yield stress and $Q_{\infty}$ the asymptotic value of the flow stress, $b$ the isotropic hardening exponent and $\mathrm{C}$, are material parameters.

The kinematic hardening is described by:

$$
\dot{\alpha}=C \frac{1}{\left.\sigma\right|_{0}}(\sigma-\alpha) \dot{\bar{\varepsilon}_{p}}-\gamma \alpha \dot{\bar{\varepsilon}}
$$

where $C$ and $\gamma$ are material parameters and $\dot{\bar{\varepsilon}}_{p}$ represents the equivalent plastic strain rate and can be written as a function of the plastic strain rate as follows:

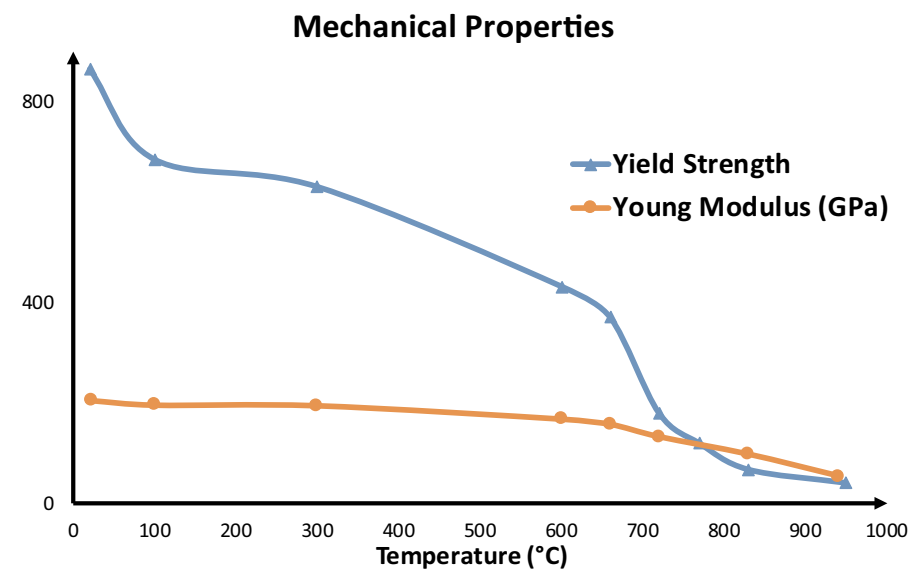

Fig. 3. Temperature dependent mechanical properties. 
Table 3

Non-linear combined hardening parameters. Source

[9].

\begin{tabular}{ll}
\hline Parameter & Value \\
\hline$\left.\sigma\right|_{0}$ & $723.6 \mathrm{MPa}$ \\
$\mathrm{Q}_{\infty}$ & $-141.6 \mathrm{MPa}$ \\
$\mathrm{B}$ & 1.42 \\
$\mathrm{C}$ & $2.4410 \mathrm{E}+5 \mathrm{MPa}$ \\
$\gamma$ & $1379 \mathrm{MPa}$ \\
\hline
\end{tabular}

$$
\dot{\bar{\varepsilon}}_{p}=\sqrt{\frac{2}{3} \dot{\varepsilon}_{p}: \dot{\varepsilon}_{p}}
$$

This model has six material parameters, $\left.\sigma\right|_{0}, Q_{\infty}, b, C$, and $\gamma$. For R4 steel grade they take the can be found in [9] and are presented in Table 3:

The geometry of this model is presented in Fig. 4:

An important characteristic of this model is the formulation of the contact between chain links. From a physical point of view, when contact takes place, a normal force to the surface of contact and a shear force are transmitted. Contact is intrinsically a nonlinear phenomenon. The contact pressure between the contact surfaces is defined as a function of the penetration distance between the contact surfaces. Hard contact definition has been chosen, it does not allow the transfer of tensile stress across the interface nor penetration between contact surfaces. It has been enforced using penalty method, which allows some small penetration, consequently improving the convergence rate. Moreover, the penetration distance is generally negligible.

Shear force is defined by the frictional model. Fiction between chain links has been modelled as an isotropic Coulomb law. Experiments have illustrated that friction coefficient $\mu$ is close to 0.3 in salt water and 0.5 in air [8]. A friction coefficient of 0.3 has been used in this study.

The geometry has been meshed with 3D solid quadratic elements with reduced integration (C3D20R). Compared to linear elements, they have a higher computational burden, although when subjected to bending they capture stress concentrations better and are more accurate. As shown in Fig. 4, the right hand side link (where the load is applied) has been meshed with a finer mesh, especially at the potential fatigue failure locations (Kt Point, the Crown, these locations are reported in Fig. 2). This has two advantages, the first one it reduces the memory requirements of the analysis, the second one, it improves the contact convergence rate between chain links, since a finer mesh of the slave part will avoid penetration and improve convergence.

\subsection{Results: residual stresses after heat treatment}

A contour plot of the hydrostatic stress (Let's recall that is defined as the average of the trace of the stress tensor) remaining after quenching is displayed in Fig. 5. The figure highlight's that after quenching high compressive residual stress (the value is near the yield strength of the steel, reported in Table 1) remains at the surface while tensile at the core. This distribution is characteristic of quenched cylinders, as reported by different authors [47-49]. Aligned with this, Fig. 6 presents the residual stress distribution in a cross section of the chain link expressed in local cylindrical coordinates. Again, compressive residual stresses are found at the surface and tensile at the core. This figure highlights the multiaxiality of the residual stress tensor.

For fatigue analysis, residual stresses are specially of interest at the surface. Fig. 7 illustrates the evolution of the stress in the hoop direction at the Crown. At the end of the quench, high compressive residual stresses remain in the chain surface. Fig. 7 reveals that when the chain is tempered the material softness and residual stresses are partially relaxed. Heat treatment ends with water cooling, which has a similar effect as quenching, it generates compressive residual stress at the surface. Finally, it is worth reminding that

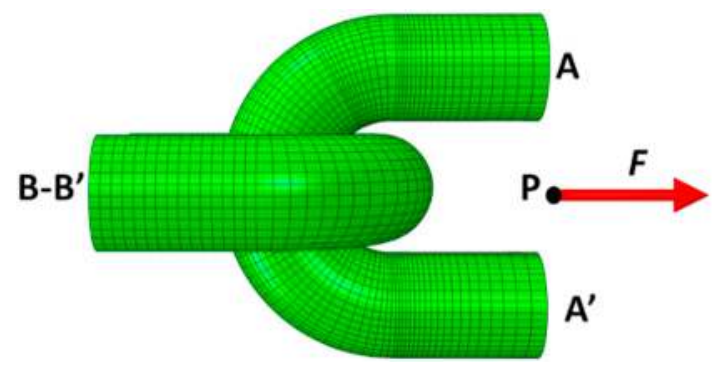

Fig. 4. Geometry and boundary conditions of FEA model.

The boundary conditions are the following:

Sections B-B': Symmetry boundary conditions.

Sections A-A' are coupled with the reference point $P$. The displacements of this point are restrained in all the directions except the direction of the applied load $F$. The external loading is applied at reference point $P$. The value of the Proof load has been specified in Table 2 . 


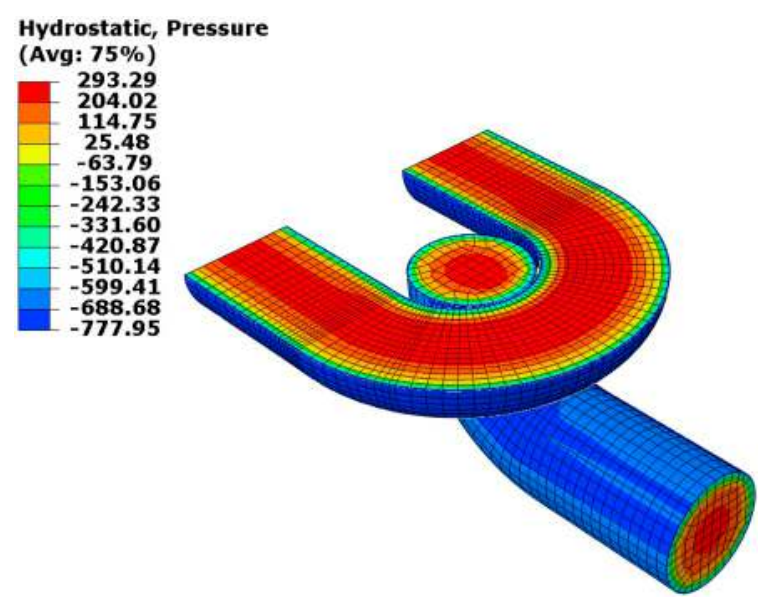

Fig. 5. Hydrostatic residual stress distribution after quench.

Tangential Residual Stresses (T-axis)

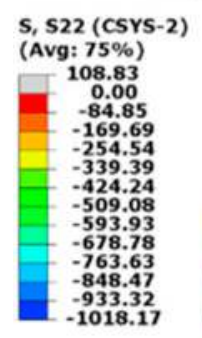

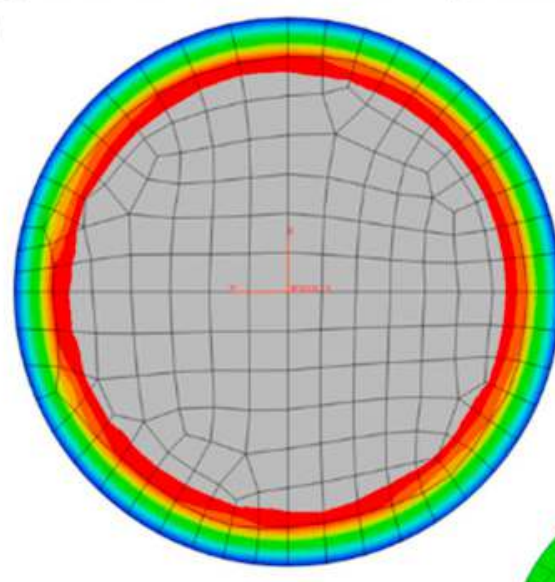

Axial Residual Stresses (Z-axis)

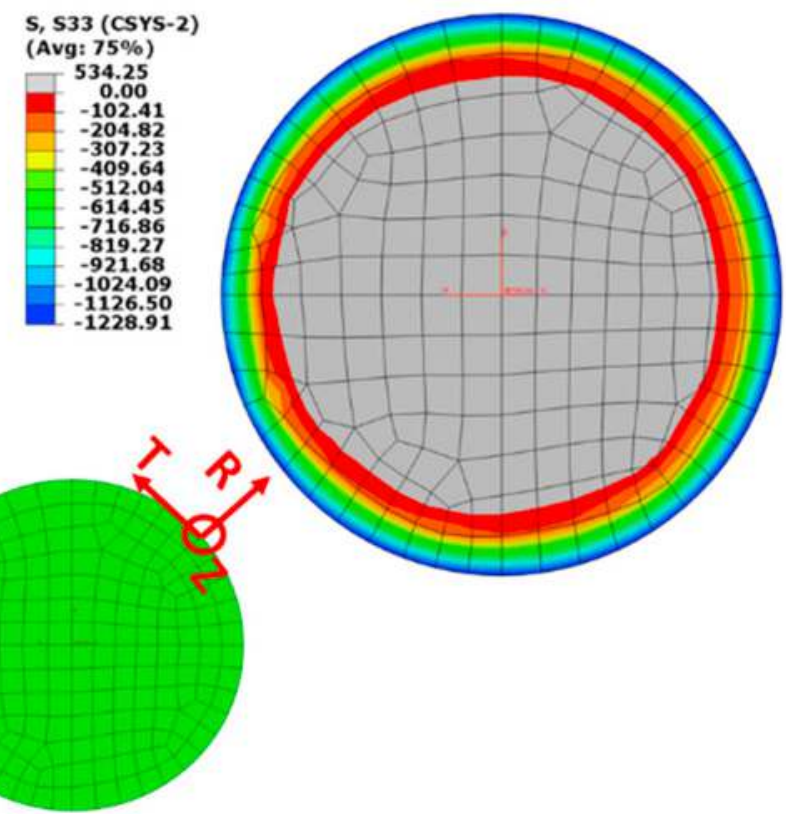

Fig. 6. Residual stress distribution after quenching at the mid section of the chain link expressed in local cyclindrical coordiantes.

phase transformation have not been accounted, the effect of phase transformation would be to reduce the magnitude of the compressive thermal stresses at the surface [51], although this reduction is not expected to vary significantly the predicted results. As said before the microstructure of mooring chain steel is composed of martensite and bainite [15-17].

\subsection{Results: final residual stress field after manufacturing (tensile loading model)}

After heat treatment and Proof load significant compressive residual stresses remain at the Crown and the Kt point, as illustrated by Fig. 8. Let's recall that these are the locations where fatigue failure take place. In addition, residual stresses are more compressive at Kt point than at the Crown. Unlike the von Mises stress, hydrostatic stress gives information about the nature of the stress distribution, compressive or tensile. The figure also reveals that high tensile residual stresses are found at the boundary of the contact zone and at a location midway between the intrados and the extrados of the link's axis. Those locations with high tensile residual stresses have already been identified by Bastid and Smith [20], although they only took into account Proof load as source of residual stresses.

Fig. 9 highlights that as expected, there is no relative displacement between contact surfaces of the chain links during Proof load. Furthermore, it also shows that high normal contact forces are predicted. 


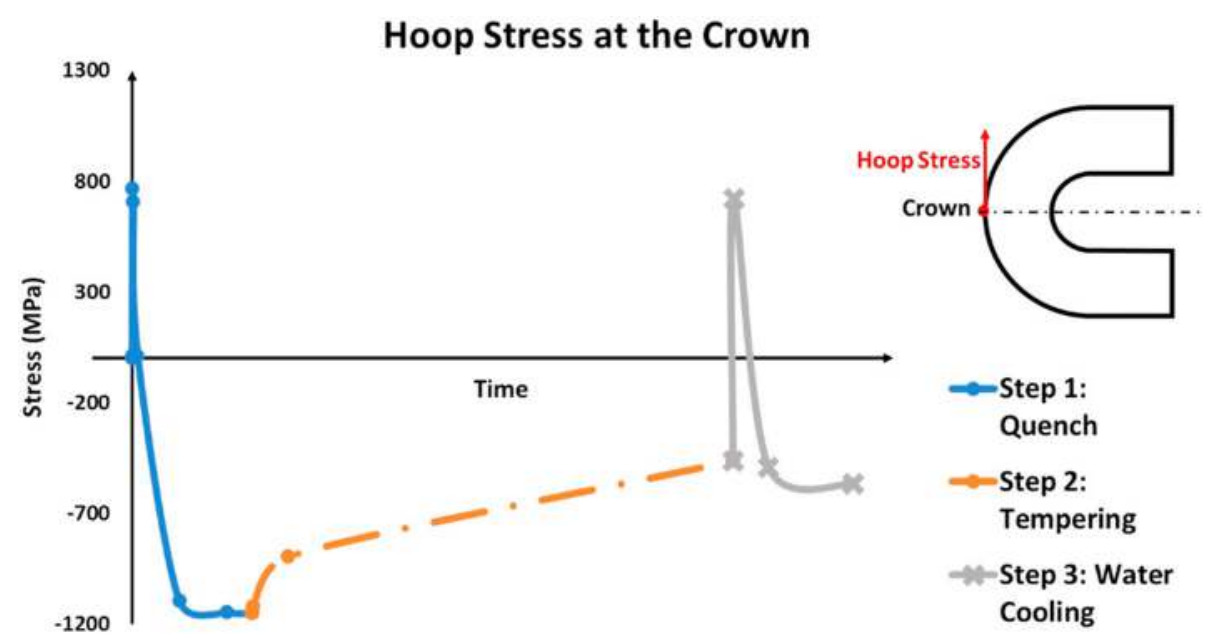

Fig. 7. Evolution of thermal stress in the hoop direction at the crown during heat treatment.

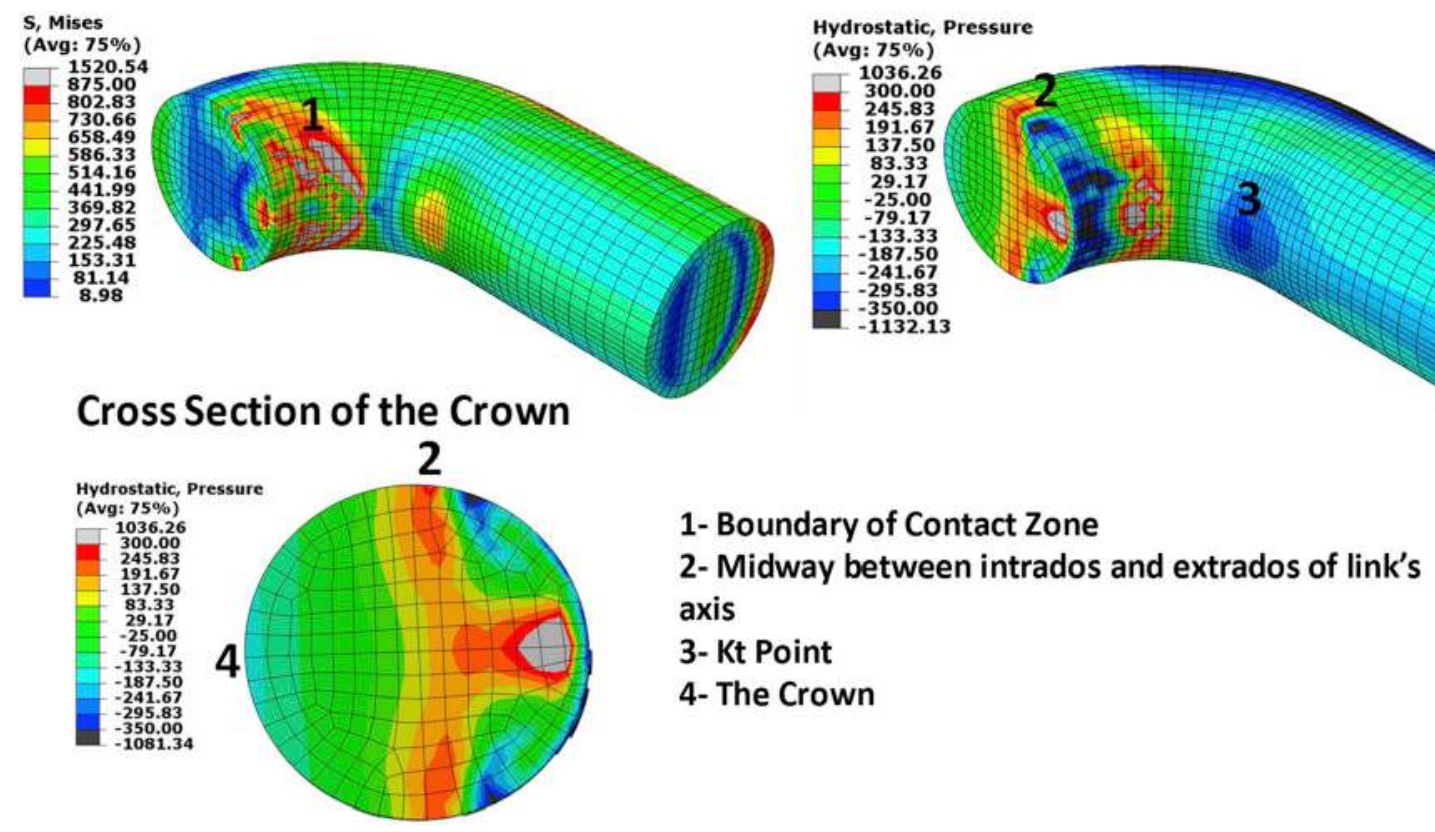

Fig. 8. Hydrostatic and von Mises Residual Stress distributions after Heat treatment and Proof load.

\subsection{Results: service loading (Tensile loading model)}

Residual stress prediction is followed by the analysis of service loading, it is the last stage of the mechanical analysis. The aim of this analysis is to derive the asymptotic response of the chain when subjected to fatigue loading.

Service loading is defined as the external force applied to the chain links and characterized by a periodic function. It has been referred as a percentage of the Minimum Breaking Load (MBL) of the chain, reported in Table 2. Fig. 10 presents the stress versus strain at the crown under proof loading, unloading and service loading. Service loading corresponds with a mean load of $20 \% \mathrm{MBL}$ and a load amplitude of $8 \%$ MBL. The graph highlights that the chain reaches a stabilized state of elastic shakedown.

\section{Fatigue analysis}

The Dang Van fatigue criterion has been selected for the fatigue analysis. It has already been used for the fatigue assessment of mooring chains under OPB [7,9]. 


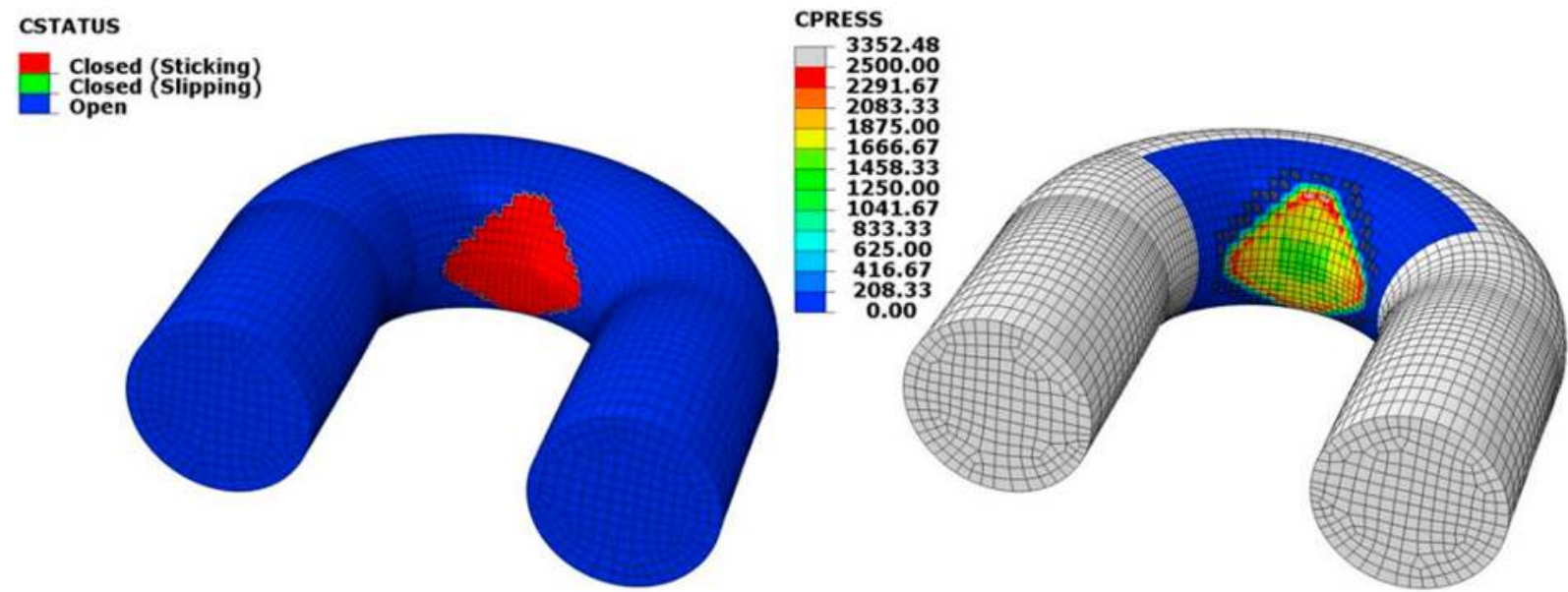

Fig. 9. Contact beteeen chain links during Proof load.

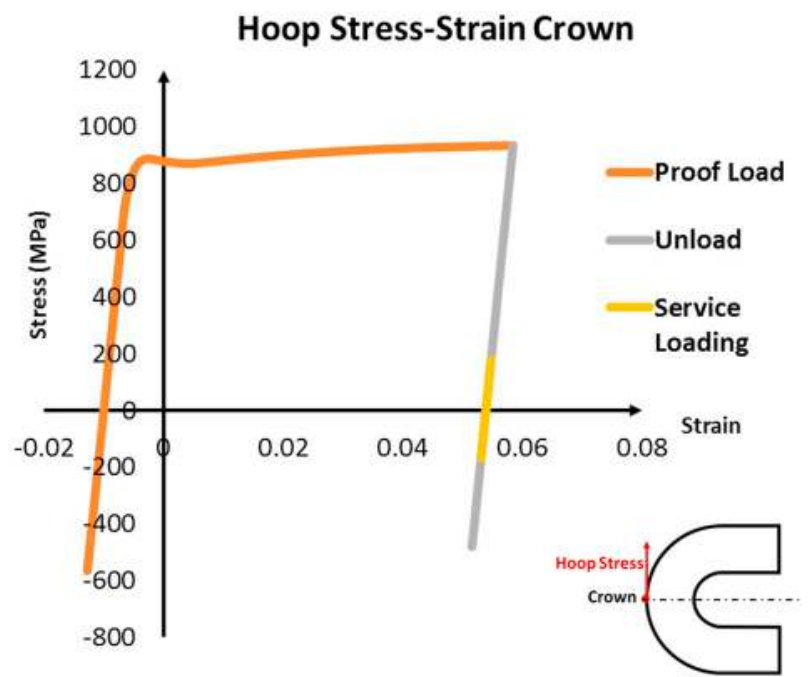

Fig. 10. Stress-Strain in the Hoop direction during Proof Load and Service loading (20\% MBL mean load and $8 \%$ MBL load amplitude).

\subsection{Dang Van fatigue criterion}

The Dang Van criterion [31,32] defines the fatigue damage as a linear combination of the maximum mesoscopic shear stress and the hydrostatic stress. It states that fatigue failure will not take place if the following inequality is satisfied.

$$
\max _{t}\left[\tau(t)+a \cdot \sigma_{h}(t)\right]<b
$$

where: $\tau(t)$ : Maximum mesoscopic shear stress. $\sigma_{h}(t)$ : Hydrostatic stress. $a$ and $b$ are material parameters.

Dang Van criterion is an endurance criterion. Nevertheless, it can be also be implemented for finite fatigue life [52-54] by defining material parameters $a$ and $b$ as a function of the number of cycles to failure.

Engineers work with macroscopic stresses (for example obtained from FEM calculations). Under the assumption of elastic shakedown at the macroscopic scale and based on Lin-Taylor hypotheses, Dang Van derived a change of scale expression that enables to derive mesoscopic stresses from macroscopic ones:

$$
\widetilde{\sigma}=\sigma(t)-\mathbf{S}^{*}
$$

where: $\widetilde{\sigma}$ : Stress tensor at mesoscopic level. $\sigma(t)$ :Stress tensor at the macroscopic level in the elastic shakedown state.S*: Represents the local residual stress state and characterizes the local stress fluctuation at the mesoscopic level. Under elastic shakedown, it is time independent and can be computed as the centre of the smallest hypersphere that circumscribes the path of the stress deviator.

The effect of mean stress is accounted in Eq. (10) by the term hydrostatic stress.

A description of the implementation of the Dang Van criterion is presented in Appendix A. 


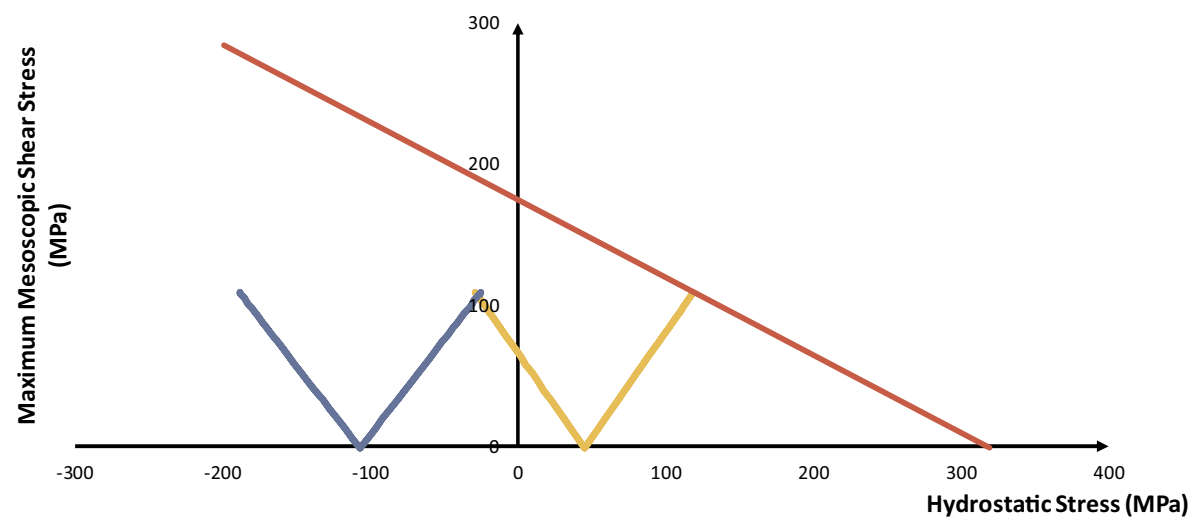

Crown -Kt Point -Dang Van Locus $\mathrm{N}=1.13 \mathrm{E}+5$

Fig. 11. Dang Van diagram for a $127 \mathrm{~mm}$ R5 chain link subjected to a mean load of $20 \% \mathrm{MBL}$ and a load amplitude of $8 \% \mathrm{MBL}$.

\subsection{Fatigue prediction: mean load: $20 \% M B L$, load amplitude: $8 \% M B L$}

The fatigue lifetime prediction corresponding to a cyclic loading of 20\%MBL load amplitude and $8 \%$ MBL mean load is presented. Fig. 11 presents the Dang Van diagrams for the locations that govern fatigue lifetime, Kt and the Crown (presented at Fig. 2).

Fig. 11 reveals that for the loading considered, the Crown is the location determining the fatigue lifetime of the chain. Also, it can be concluded that the Crown and Kt have the same maximum mesoscopic shear stress, they are only differentiated by the hydrostatic stress (which accounts for the combined effect of mean load and residual stresses). Fig. 12 presents the Dang Van load paths for both locations with and without accounting for residual stresses.

Fig. 12 highlights how residual stresses from the manufacturing process delay the fatigue failure by shifting towards the left the Dang Van path. This effect is more significant at Kt than at the Crown.

\section{Comparison with experiments}

The predictions derived from the fatigue assessment method have been compared with experimental data. The comparison has been done in two different stages. First a qualitative comparison has been performed. The criterion has been applied at all the nodes of the surface of the chain link. The aim is to check whether the predicted fatigue failure locations, by Dang Van criterion, correspond with the locations where chains are known to fail (Kt point and the Crown, both reported in Fig. 2). Second, the predicted fatigue lifetimes have been compared against the lifetimes obtained from fatigue testing of mooring chains under saline water flow.

\section{Effect of Residual Stresses}

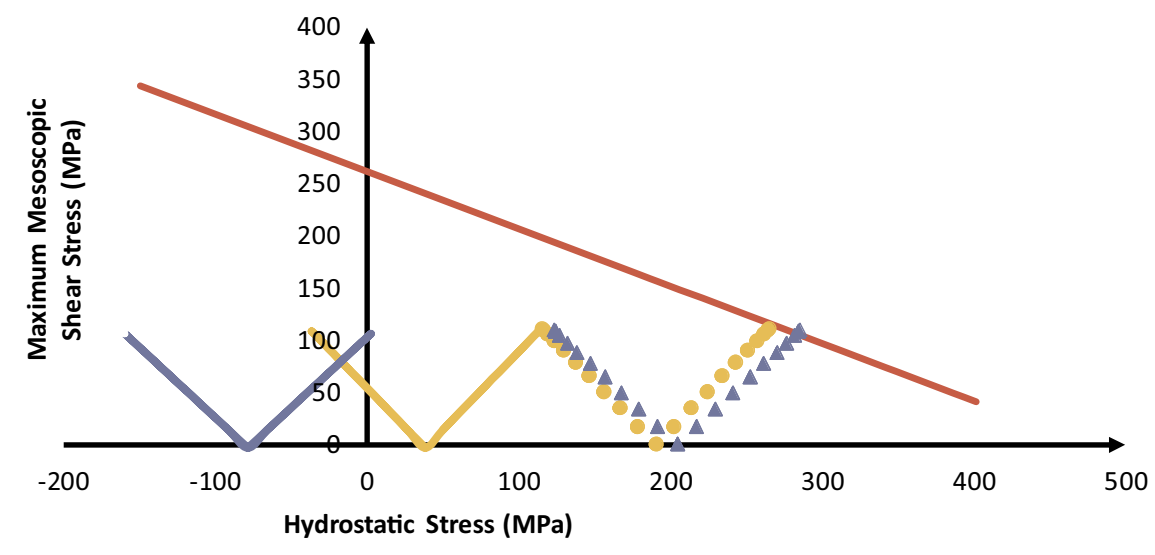
-Dang Van Locus

Crown: No Residual Stresses accounted

$\Delta \mathrm{Kt}$ : No residual Stresses accounted

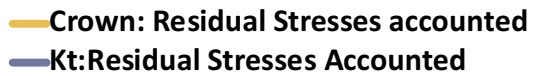

Fig. 12. Effect of Residual Stresses at the fatigue failure locations of mooring chain links. 


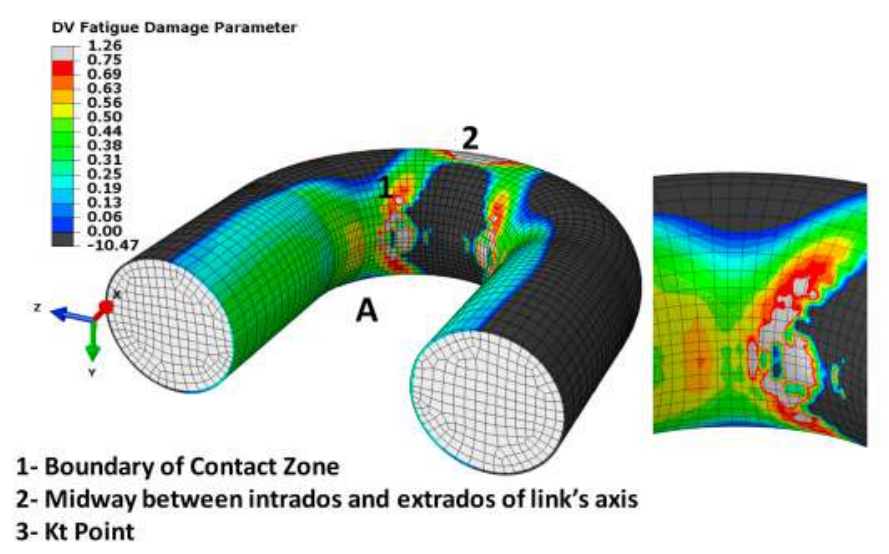

Fig. 13. Contour Plot of the Dang Van Fatigue damage parameter and Zoom in at the boundary of the contact zone.

\subsection{Qualitative comparison}

As described in Annex A, the use of BFGS optimization method has enabled to apply the Dang Van fatigue criterion at 11960 nodes in less than $4 \mathrm{~min}$ using a standard desktop computer. For each node, the following damage indicator was computed:

$$
C_{D V}=\left[\frac{\max \left[\tau(t)+a(N) \cdot \sigma_{H}(t)\right]-b(N)}{b(N)}\right]
$$

Fig. 13 presents a contour plot of the Dang Van fatigue damage parameter. Surprisingly, it unveils that the two most critical locations were neither the Kt point nor the crown, they are the region at the boundary of the contact zone (Region 1 ) and the region midway between the intrados and the extrados of the link axis (Region 2). Fig. 14 illustrates the Dang Van load path for the locations reported in Fig. 13.

Fig. 14 highlights that at the boundary of the contact zone (Region 1) and midway between intrados and extrados of link's axis (Region 2) hydrostatic stress is significantly bigger compared to mesoscopic shear stress amplitude. This fact can be explained by looking the values of residual stresses at these locations. As already reported in Fig. 8, residual stresses take high tensile values at Region 1 and Region 2. Moreover, this is in agreement with the results from Bastid and Smith [20], who predicted principal residual stresses of $1512 \mathrm{MPa}$ and $710 \mathrm{MPa}$ at Region 1 and Region 2 respectively by means of elastic-plastic finite element analysis. They only accounted for residual stresses from proof loading. At first, it could be considered that these high values were predicted because heat

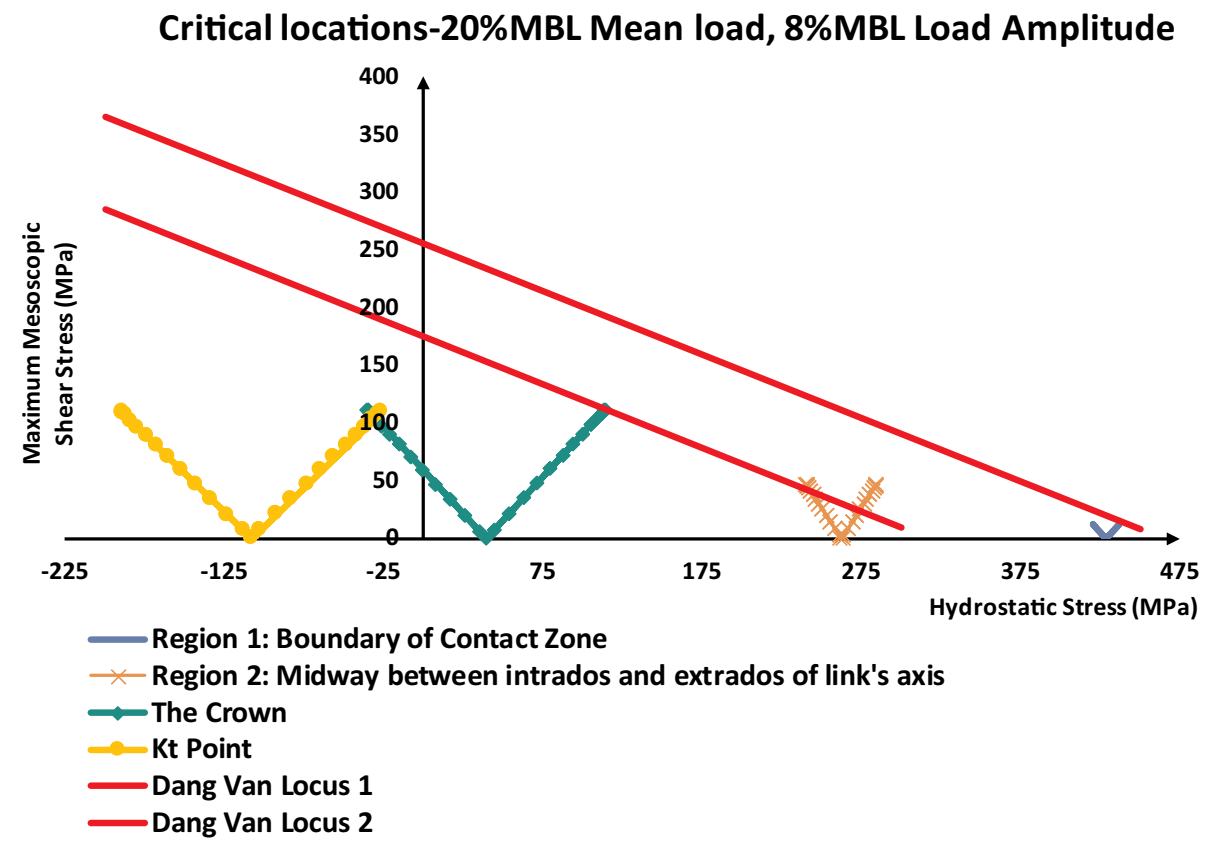

Fig. 14. Dang Van load paths of the predicted fatigue failure locations. 
treatment has not been accounted for. In fact, when heat treatment is considered, these values are reduced, but are still important. For a $127 \mathrm{~mm}$ R5 chain the predicted residual stress values accounting for heat treatment and Proof loading are $625 \mathrm{MPa}$ and $450 \mathrm{MPa}$ at Region 1 and Region 2 respectively. In other words, even if heat treatment is considered in the prediction of residual stresses, high tensile residual stresses are still derived at both regions.

Dang Van Fatigue criterion is of phenomenological nature. Similar to critical plane methods, it is based on the mechanisms that govern fatigue crack initiation. It considers that crack initiation is driven primarily by shear stress amplitude, having hydrostatic stress a secondary although important role. Susmel et al. [55] addressed that when the ratio between maximum normal stress and shear stress amplitude relative to the critical plane attaints an upper value, critical plane criteria have no longer physical sense. In other words, failure is not governed any more by the mechanisms which are the base of critical plane methods. The critical plane stress ratio is defined as follows:

$$
\rho=\sigma_{n, \max } / \tau_{a}
$$

The mechanisms that govern static failure are different from the mechanisms of fatigue failure. When $\rho$ takes high values, we are closer to a static problem rather than to a fatigue problem. In these cases, lifetime will not be governed anymore by shear stress amplitude. Critical plane approaches can be applied as long as the critical plane stress ratio remains below a certain value, in other words, as long as shear stress amplitude is significant compared to mean stress.

Susmel et al. [55] derived an equation to obtain the limit value of the critical plane stress ratio, although the expression of this ratio might change from one criterion to another, it gives an initial approximation of a threshold for which critical plane approaches can be used. The limit value is dependant of the material fatigue material properties, and is the defined as follows:

$$
\rho_{\lim }=\frac{\tau_{A, \infty}}{2 \cdot \tau_{A, \infty}-\sigma_{A, \infty}}
$$

In the case of R5 grade for corroded specimens and a fatigue lifetime of 10E6 cycles, the limit value is around 1.81. The critical plane stress ratio was calculated for Region 1 and Region 2, obtaining values of 35 and 6.5 respectively. Therefore, at these locations critical plane should not be used, they do not have a physical sense since shear stress amplitude is small compared to normal stress, as already reported in Fig. 14. Moreover, at these locations, there is a competition between the negative effect of damage and the beneficial effect of hardening [56]. In addition, the Dang Van locus should be modified at the high hydrostatic region, it should be derived from fatigue tests performed on notched specimens and account for the positive effect of hardening [57].

Excepting Region 1 and Region 2, the most critical locations according to the Dang Van fatigue criterion are the Crown and Kt. In fact, for a $20 \%$ MBL mean load, the Crown was found to be the location governing the fatigue lifetime of the mooring chain links. This was confirmed by fatigue testing (more details are provided in the following section), most of the fatigue failures occurred at the Crown. These failure locations under tension loading are in agreement with the literature [14,44]. Fig. 15 and Fig. 16 report fatigue cracks that led to failure at Kt Point and the Crown respectively.

\subsection{Quantitative validation: comparison with experimental results}

As part of a Joint Industry Project lead by TWI Ltd., fatigue testing of mooring chains under saline solution flow has been performed. The fatigue results have been compared with the predicted fatigue lifetimes by the computational fatigue assessment. A $127 \mathrm{~mm}$ R5 chain has been tested at different mean loads and load amplitudes ranging between 3.75\%MBL and 8\%MBL. In this project, full scale fatigue testing of mooring chain was carried out in air and $3.5 \% \mathrm{NaCl}$ solution under tension-tension loading, at loading frequencies between 0.2 and $0.5 \mathrm{~Hz}$ at a temperature around $10{ }^{\circ} \mathrm{C}$. Each chain segment was composed of seven links. Once a link failed, it was replaced with a Kenter link to continue the tests till three link failures in each segment had been achieved. Most tests were achieved at a mean stress equal to $20 \% \mathrm{MBL}$, while one test at a $10 \% \mathrm{MBL}$.

The predicted fatigue lifetimes by the computational fatigue assessment have been compared with experimental results.

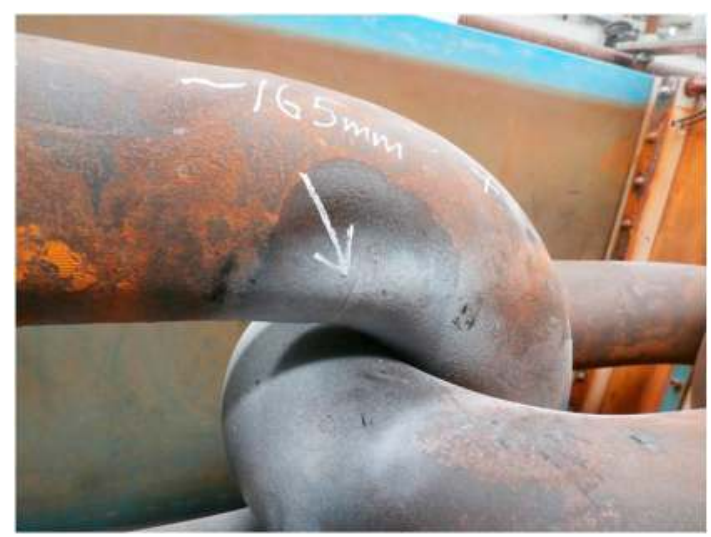

Fig. 15. Fatigue crack at the Kt position. 

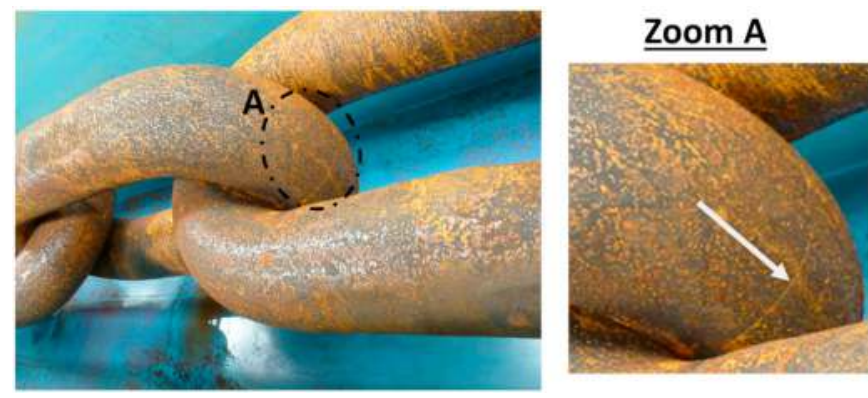

Fig. 16. Fatigue crack at the Crown.

\subsubsection{Mean load 20\%MBL}

Different load amplitudes have been tested at a 20\%MBL mean load, in total 48 test were carried out. The difference between the logarithmic values of the estimated and predicted lifetimes is presented at (Fig. 17) under the form of a histogram. The distribution of the error has been fit with a normal distribution. The mean value of this distribution is 0.05 while the standard deviation is 0.13 . Consequently, on average Dang Van fatigue criterion tends to predict fatigue lifetimes that are 1,12 times lower (therefore conservative) than the experimental fatigue results. Moreover, a small standard deviation indicates that the estimation error tends to be concentrated near the mean value.

\subsubsection{Mean load $10 \% M B L$}

As already reported by Martinez Perez et al. [58], mean load has an influence in the fatigue performance of mooring chains. For low mean loads, (for example 10\% MBL), they suggested to use the modified Dang Van locus proposed by Desimone et al. [59], who modified the Dang Van locus by dividing it in two parts. For positive hydrostatic stresses the locus remains unchanged, while for lower hydrostatic stress values the locus becomes horizontal (Reported in Fig. 18). This modification is a conservative approach which avoids overestimating the predicted fatigue lifetime for high compressive mean stresses, which is a drawback of the Dang Van fatigue criterion, already pointed by different authors [60-63].This modified Dang Van locus has been applied by different authors for studying Rolling Contact fatigue [61,63].

For a 10\%MBL mean load, the fatigue lifetimes predicted by both locus (the original proposed by Dang Van [31,33] and the modified locus proposed by Desimone [59]) are reported in Fig. 19.

Fig. 19 highlights the difference between the fatigue lifetime predicted by both loci. When the modified conservative locus proposed by Desimone et al. [59] is applied, the definition of the failure location is ambiguous, since at both locations the maximum mesoscopic shear stress takes the same value. In other words, the chain is likely to fail indistinctively at the Crown or Kt. Only one fatigue test at a low mean load was performed. The Modified Conservative Locus by Desimone et al. [59] matched better with the experimental result, being the difference of the logarithms of the predicted and measured fatigue lifetime less than 0.075 .

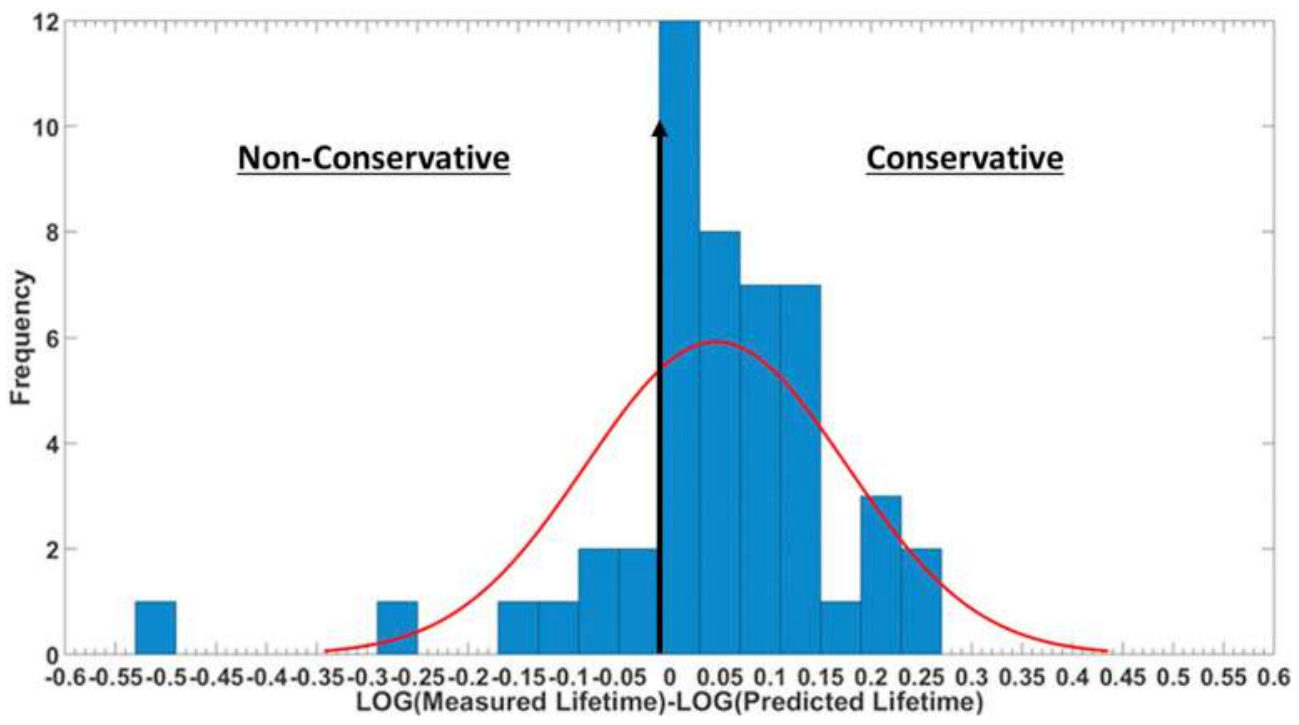

Fig. 17. Histogram of the Dang Van Prediction for a $127 \mathrm{~mm}$ R5 chain link under a 20\%MBL mean load. 


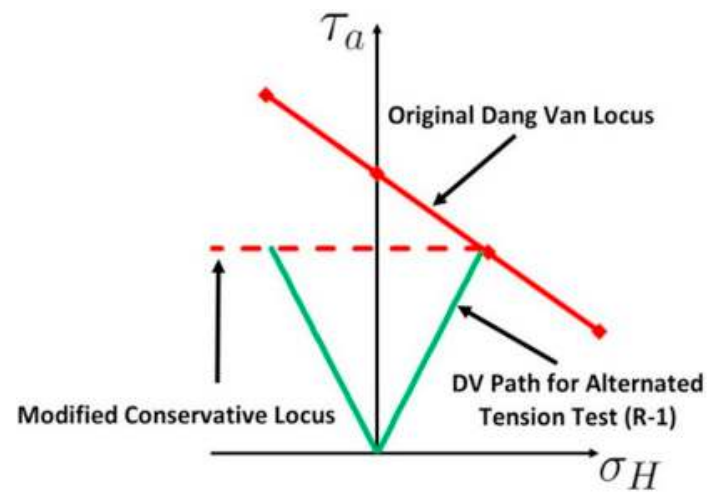

Fig. 18. Original and Modified Dang Van Locus for the compressive hydrostatic stress region.

\section{Conclusion and discussion}

This paper has addressed the fatigue lifetime prediction of mooring chains under tension loading from a global approach. First, a residual stress prediction accounting for the manufacturing has been performed. Second, cycling loading has been imposed for deriving the stabilized response of the chain. Finally, the Dang Van criterion has been applied. The following conclusions have been drawn:

- For mooring chains working at high mean loads (20\% MBL) the Dang Van criterion has yielded fatigue predictions that are close to experimental results. This has been concluded after comparing the predicted lifetimes with 48 fatigue tests.

- For mooring chain working at low mean loads (10\%MBL) the Modified Conservative Locus proposed by Desimone et al. [59] gave a fatigue prediction closer to experimental results than the original Dang Van locus. Desimone et al. [59] considered that the beneficial effect of compressive residual stresses on the fatigue lifetime is bounded. However, it is important to keep in mind that only one fatigue test was performed at a low mean load. More fatigue testing both in chains and in small specimens should be done in order to understand better the behaviour at the region of high compressive hydrostatic stress values.

\section{Acknowledgements}

The work presented in this paper has been carried out under a PhD sponsored by TWI Ltd. and University of Edinburgh at NSRIC (National Structural Integrity Research Centre). The main author would like to thank these institutions for this opportunity. Moreover, part of this work was done as a visiting research student at LMS, CNRS Ecole Polytechnique (France) partially founded by an ERASMUS Grant.

Finally, the experimental data used for the validation of the computational fatigue assessment was kindly provided by a Joint Industry Project lead by TWI Ltd. whose sponsors are: American Bureau of Shipping (ABS), BP Exploration Operating Co Ltd., Shell Projects and Technology (former BG group), Equinir, Ramnäs Bruk (in kind) and Vicinay Cadenas (in kind). The authors are grateful to these companies for the permission to publish these results. Their contribution has been of great value for the validation.

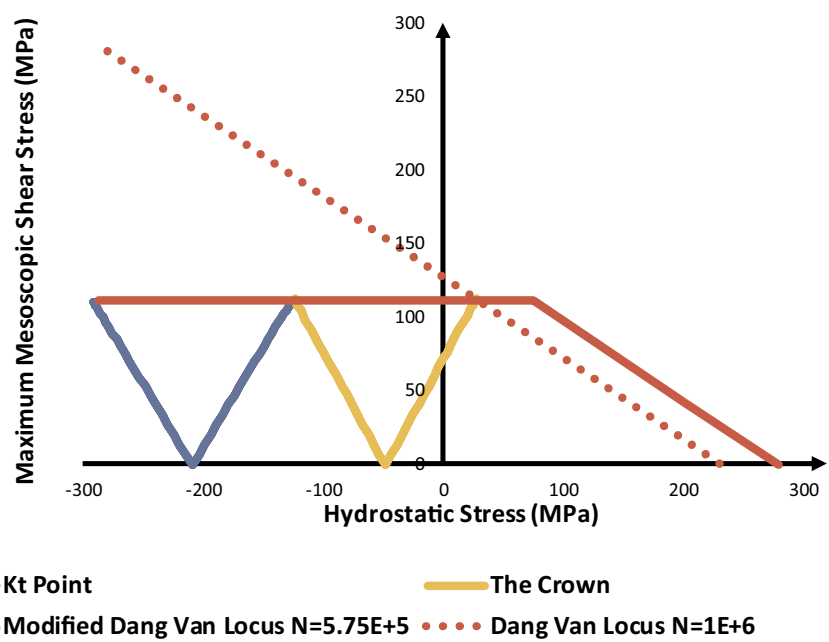

Fig. 19. Comparison between the predictions of the Original and the Modified Dang Van Locus. 


\section{Appendix A. Implementation of the fatigue criterion}

The fatigue analysis has been performed by post processing the results from the mechanical analysis with MATLAB. There are three aspects to which attention has been paid in order to apply the criterion accurately and in a reduced computational time. The first one, relates to the mathematical points at which the criterion is applied, the second one, how to derive mesoscopic stresses from macroscopic ones. Finally, the third one, the calibration of the material parameters $a$ and $b$ of the fatigue criterion.

Because of the high stress gradient predicted in the region of the Kt point (as illustrated in Fig. 8), the value of the stress at the integration point is not representative of the peak stress at the element. The stress values extrapolated at the nodes of elements with quadratic interpolation were thought to be more reliable for this analysis, Consequently, in this study, the fatigue criterion has been applied at the nodes, rather than at the integration points.

From a calculation point of view, when solving Eq. (11) the main challenge is to obtain $\mathbf{S}^{*}$. It can be calculated through computational geometry [64] although most of the applications in the literature use optimization methods (for example [52,65-67]) or in textbooks [68], and obtain as $\mathbf{S}^{*}$ :

$$
\mathbf{S}^{*}=\min _{s^{*}} \max _{t}\left\|\mathbf{s}-\mathbf{s}^{*}\right\|
$$

In this study BFGS optimization method has been used for solving Eq. (A.1).The MATLAB code HANSO [69], available at [70], which is based on BFGS method but performs an inexact line search has been employed. This method is fast in terms of computational time. Moreover, unlike other optimization methods, for example Nelder-Mead Simplex [71], it provides good results when the smoothness of Eq. (4) is not guaranteed. Another advantage of this methods is that since it uses the information provided by the gradient, it requires less iterations to converge than Nelder-Mead Simplex. To our knowledge BFGS has not been used before in the context of fatigue analysis, nevertheless it has enabled a fast fatigue assessment of the chain link, taking less than 4 min to analyse 11,960 nodes.

As a final aspect to be considered, is the calibration of the criterion. The predicted lifetimes depend on the material parameters $a$ and $b$. These parameters can be obtained from simple test on small specimens, for example alternated tension and alternated torsion. In this case, the expression of the parameters is the following:

$$
a(N)=\frac{\tau_{N}-\frac{\sigma_{N}}{2}}{\frac{\sigma_{N}}{3}} b(N)=\tau_{N}
$$

where:

$\tau_{N}$ : Alternated torsion fatigue strength for $N$ cycles.

$\sigma_{N}$ : Alternated tension fatigue strength for $N$ cycles.

Mooring chains work in a corrosive environment, seawater. Consequently, fatigue properties accounting for corrosion should be used for deriving material parameters $a$ and $b$. The assumption that $a$ remains constant with the number of cycles has been made. This assumption is commonly made when applying Dang Van for finite fatigue life [52,53]. For mooring chain steel under corrosion it takes a value of 0.55 [9]. Therefore, only $b$ remains to be calculated, it can be rewritten as a function of a and the alternated fatigue strength as follows:

$$
b(N)=a \cdot \frac{\sigma_{N}}{3}+\frac{\sigma_{N}}{2}
$$

There are two different approaches for deriving fatigue properties (alternated torsion and tension fatigue strengths) accounting for corrosion, the first one is to pre-corrode specimens (for example following the standard EN ISO 9227) and perform fatigue testing in air, the second one is to perform the testing under sea water flow. Corrosion is a time dependent phenomenon, for a given loading conditions, decreasing testing frequency is expected to decrease the fatigue lifetime. Just to give an example, Endo and Miyao [72] found that in the range of 1E6 and 1E7 cycles, varying the test frequency from $42.5 \mathrm{~Hz}$ to $4.08 \mathrm{~Hz}$ of a carbon low alloy steels tested in a saline solution, decreased the fatigue lifetime by $50 \%$.

The fatigue properties of R5 steel grade accounting for corrosion have been published by different authors, Perez Mora [19,20], Fernandez et al. [14] and Arredondo et al. [73]. All the datasets were obtained from specimens under tension loading. On the one hand, Perez Mora obtained fatigue properties of R5 steel of small specimens under sea water flow tested at $20 \mathrm{kHz}$ and small precorroded specimens tested on air. On the other and, the second and third authors presented fatigue tests on small specimens tested at $0.5 \mathrm{~Hz}$. Following the discussion about the dependency of the fatigue properties on the test frequency presented before, the data from Fernandez et al. [14] and Arredondo et al. [73] has been used. In addition, fatigue properties from a report [74] have also been employed for calibrating the Dang Van fatigue criterion.

A slope of 3 (value recommended by API-RP2SK [29] and DNVGL- OS- E302 [41] for mooring chain steel under sea water) has been used for interpolating the fatigue limit as a function the number of cycles. 


\section{References}

[1] E. Fontaine, C. Carra, D. Washington, K. Ma, A. Phadke, D. Laskowki, G. Kusinski, Industry Survey of Past Failures, Pre-Emptive Replacements and Reported Degradations for Mooring Systems of Production Units, Offshore Technology Conference, 2014.

[2] A. Kvitrud, Lessons learned from Norwegian mooring line failures 2010-2013, ASME 2014 33rd International Conference on Ocean, Offshore and Arctic Engineering, American Society of Mechanical Engineers, 2014(p. V04AT02A005-V04AT02A005).

[3] Kai-Tung Ma, Arun Duggal, Philip Smedley, A historical review on integrity of permenent mooring systems, Offshore Technology Conference, Houston Texas, 2013.

[4] R. D'Souza, S. Majhi, Application of Lessons Learned from Field Experience to Design, Installation and Maintenance of FPS Moorings, Offshore Technology Conference, 2013.

[5] M.G. Brown, T.D. Hall, D.G. Marr, M. English, R.O. Snell, et al., Floating production mooring integrity JIP-key findings, Offshore Technology Conference, Offshore Technology Conference, 2005

[6] E. Funnemark, E. Young, Great Britain, Health and safety executive, and Norske Veritas (organization), Accident Statistics for Fixed Offshore Units on the UK Continental Shelf, 1980-2001, HSE Books, Sudbury, 2003.

[7] L. Rampi, F. Dewi, P. Vargas, Chain out of Plane Bending (OPB) Joint Industry Project (JIP) Summary and Main Results, Offshore Technology Conference, 2015.

[8] P. Jean, K. Goessens, D. L'Hostis, et al., Failure of chains by bending on deepwater mooring systems, Offshore Technology Conference, Offshore Technology Conference, 2005.

[9] L. Rampi, A. Bignonnet, C. Le Cunff, F. Bourgin, P. Vargas, Chain out of plane bending (OPB) fatigue joint industry project (JIP) FEA results and multiaxiality study results, ASME 2016 35th International Conference on Ocean, Offshore and Arctic Engineering, American Society of Mechanical Engineers, 2016(V001T01A002-V001T01A002).

[10] J. Rosen, K. Jayasinghe, A. Potts, SCORCH JIP: Findings from Investigatins into Mooring Chain and Wire Rope Corrosion in Warm Waters, Offshore Technology Conference, 2015.

[11] E. Fontaine, J. Rosen, A. Potts, K. Ma, R.E. Melchers, SCORCH JIP - Feedback on MIC and Pitting Corrosion from Field Recovery Chain Links, Offshore Technology Conference, 2014.

[12] Fontaine, E., Potts, A., Ma, K., Arredondo, A., and E.Melchers, R., 2012, "SCHORCH JIP: Examination and Testing of Severely-Corroded Mooring Chains from West Africa," Offshore Technology Conference.

[13] $\varnothing$. Gabrielsen, K. Larsen, S.-A. Reinholdtsen, Fatigue testing of used mooring chain, ASME 2017 36th International Conference on Ocean, Offshore and Arctic Engineering, American Society of Mechanical Engineers, 2017(p. V001T01A072-V001T01A072).

[14] J. Fernández, W. Storesund, J. Navas, Fatigue performance of grade R4 and R5 mooring chains in seawater, ASME 2014 33rd International Conference on Ocean, Offshore and Arctic Engineering, American Society of Mechanical Engineers, 2014(p. V01AT01A035-V01AT01A035).

[15] P.M. Ruben, Study of the Fatigue Strength in the Gigacycle Regime of Metallic Alloys Used in Aeronautics and off-Shore Industries, Arts et Métiers ParisTech, 2010.

[16] R. Pérez-Mora, T. Palin-Luc, C. Bathias, C. Paris, Very high cycle fatigue of a high strength steel under sea water corrosion: a strong corrosion and mechanical damage coupling, Int. J. Fatigue 74 (2015) 156-165.

[17] T. Palin-Luc, R. Pérez-Mora, C. Bathias, G. Domínguez, P.C. Paris, J.L. Arana, Fatigue crack initiation and growth on a steel in the very high cycle regime with sea water corrosion, Eng. Fract. Mech. 77 (11) (2010) 1953-1962.

[18] P. Pacheco, P.P. Kenedi, J.C.F. Jorge, H.S. Gama, M.A. Savi, A.M.C. Paiva, Modeling residual stresses in offshore chain links using finite element method, COBEM-2003, 17th International Congress of Mechanical Engineering, São Paulo, 2003.

[19] G.J. Shoup, S.M. Tipton, J.R. Sorem, et al., The influence of proof loading on the fatigue life of anchor chain, Offshore Technology Conference, Offshore Technology Conference, 1992.

[20] P. Bastid, S.D. Smith, Numerical analysis of contact stresses between mooring chain links and potential consequences for fatigue damage, ASME 2013 32nd International Conference on Ocean, Offshore and Arctic Engineering, American Society of Mechanical Engineers, 2013(p. V02BT02A037-V02BT02A037).

[21] M.G. Brown, A.P. Comley, M. Eriksen, I. Williams, P. Smedley, S. Bhattacharjee, Phase 2 Mooring Integrity JIP-Summary of Findings, (2010) (Texas).

[22] Bureau Veritas, Fatigue of Top Chain of Mooring Lines Due to in-Plane and Out-of-Plane Bendings, (2014).

[23] T. Lassen, E. Storvoll, A. Bech, Fatigue life prediction of mooring chains subjected to tension and out of plane bending, ASME 200928 th International Conference on Ocean, Offshore and Arctic Engineering, American Society of Mechanical Engineers, 2009, pp. 229-239.

[24] E. ter Brake, J. van der Cammen, R. Uittenbogaard, Calculation methodology of out of plane bending of mooring chains, ASME 2007 26th International Conference on Offshore Mechanics and Arctic Engineering, American Society of Mechanical Engineers, 2007, pp. 411-419.

[25] Nilakash Das, "Models to explain out-of-plane bending mechanism in mooring chain links."

[26] T. Lassen, J. Aarsnes, E. Glomnes, Fatigue design methodology for large mooring chains subjected to out-of-plane bending, ASME 2014 33rd International Conference on Ocean, Offshore and Arctic Engineering, American Society of Mechanical Engineers, 2014(p. V04AT02A029-V04AT02A029).

[27] I.J. Calf, Multiaxial Fatigue Criteria for Offshore Mooring Chains Subjected to out-of-Plane Bending, Delft University of Technology, TU Delft, 2015.

[28] I. Martinez Perez, P. Bastid, V. Venugopal, Prediction of Residual Stresses in Mooring Chains and Its Impact on Fatigue Life, (2017) (V03AT02A034).

[29] American Petroleum Institute (API), Design and Analysis of Stationkeeping Systems for Floating Structures, (2008).

[30] DNV, Position Mooring-DNV-OS-E301_2010-10, (2010).

[31] K.D. Van, I.V. Papadopoulos (Eds.), High-Cycle Metal Fatigue, Springer Vienna, Vienna, 1999.

[32] K. Dang Van, G. Cailletaud, J.F. Flavenot, A. Le Douron, H.P. Lieurade, Criterion for High Cycle Fatigue Failure under Multiaxial Loading, Biaxial Multiaxial Fatigue, 1989, pp. 459-478.

[33] Dang Van, and Maittourman, "Rolling Contact in Railways: Modeling Simulation and Damage Prediction."

[34] K.D. Van, On a unified fatigue modelling for structural analysis based on the shakedown concept, Ciênc. Tecnol. Mater. 22 (3-4) (2010) 02-11.

[35] B. Echard, N. Gayton, A. Bignonnet, A reliability analysis method for fatigue design, Int. J. Fatigue 59 (2014) $292-300$.

[36] Thomas, J., Bignonnet, A., and Perroud, G., 2005, "Fatigue design and experimentations with variable amplitude loadings in the automotive industry," Fatigue Testing and Analysis Under Variable Amplitude Loading Conditions, P. McKeighan, and N. Ranganathan, Eds., ASTM International, 100 Barr Harbor Drive, PO Box C700, West Conshohocken, PA 19428-2959, (Pp. 381-381-14).

[37] E. Charkaluk, A. Constantinescu, F. Szmytka, S. Tabibian, Probability density functions: from porosities to fatigue lifetime, Int. J. Fatigue 63 (2014) 127-136.

[38] A. Constantinescu, K. Dang Van, M.H. Maitournam, A unified approach for high and low cycle fatigue based on shakedown concepts, Fatigue Fract. Eng. Mater. Struct. 26 (6) (2003) 561-568.

[39] A. Constantinescu, A computational approach to thermomechanical fatigue, Int. J. Fatigue 26 (8) (2004) $805-818$.

[40] Dang Van, Griveau, Message, On a new multiaxial fatigue limit criterion: theory and application, Biaxial Multiaxial Fatigue (1989) 476-496.

[41] DNV, DNV-OS-E302 - Offshore Mooring Chain, (2013).

[42] International Association of Classification Societies (IACS), Requirements Concerning Materials and Welding, W22 Offshore Mooring Chain, (2011).

[43] B. Albisu, I. Salado, A. Arredondo, D. Bilbao, M. Abrisketa, J.L. Arana, Z. Idoyaga, New grades of high strength steel for offshore mooring chains: R5S (1100 MPa) and R6 (1200 MPa), Offshore Technology Conference, Offshore Technology Conference, 2016.

[44] P.M. Vargas, T.-M. Hsu, W.K. Lee, Stress Concentration Factors for Stud-Less Mooring Chain Links in Fairleads, ASME, 2004 , pp. 909-917.

[45] J. Lereim, et al., Summary of the 4-year research project: Anchor chain cables offshore, Offshore Technology Conference, Offshore Technology Conference, 1985.

[46] P.M.C.L. Pacheco, P.P. Kenedi, J.C.F. Jorge, A.M.C. de Paiva, Analysis of the Influence of Mechanical Properties on the Residual Stress in Offshore Chain Links Using the Finite Element Method, ASME, 2003, pp. 131-140.

[47] R. Schröder, Influences on development of thermal and residual stresses in quenched steel cylinders of different dimensions, Mater. Sci. Technol. 1 (10) (1985) $754-764$. 
[48] G.E. Totten, M.A.H. Howes, T. Inoue, Handbook of Residual Stress and Deformation of Steel, ASM International, Materials Park, Ohio, 2002.

[49] C.H. Gur, A.E. Tekkaya, Numerical and experimental analysis of quench induced stresses and microstructures, J. Mech. Behav. Mater. 9 (4) (1998) 237-256.

[50] P.R. Woodard, S. Chandrasekar, H.T.Y. Yang, Analysis of temperature and microstructure in the quenching of steel cylinders, Metall. Mater. Trans. B Process Metall. Mater. Process. Sci. 30 (4) (1999) 815.

[51] Quenching Technology.

[52] F. Auricchio, A. Constantinescu, M. Conti, G. Scalet, A computational approach for the lifetime prediction of cardiovascular balloon-expandable stents, Int. J. Fatigue 75 (2015) 69-79.

[53] M. Ferjani, D. Averbuch, A. Constantinescu, A computational approach for the fatigue design of threaded connections, Int. J. Fatigue 33 (4) (2011) 610-623.

[54] P. Wackers, V. Arrieta, M. Alquezar-Getan, A. Constantinescu, H. Maitournam, A modeling approach to predict fretting fatigue on highly loaded blade roots, J. Eng. Gas Turbines Power 132 (8) (2010) 082101.

[55] L. Susmel, R. Tovo, P. Lazzarin, The mean stress effect on the high-cycle fatigue strength from a multiaxial fatigue point of view, Int. J. Fatigue 27 (8) (2005) 928-943.

[56] I. Koutiri, D. Bellett, F. Morel, The effect of mean stress and stress biaxiality in high-cycle fatigue, Fatigue Fract. Eng. Mater. Struct. 41 (2) (2018) $440-455$.

[57] Koutiri, I., "Effet des fortes contraintes hydrostatiques sur la tenue en fatigue des matériaux métalliques," p. 244.

[58] I. Martinez Perez, P. Bastid, A. Constantinescu, V. Venugopal, Multiaxial Fatigue Assessment of Mooring Chain Links under Tension Loading: Influence of the Mean Load and Simplified Assessment, (2018) (V03AT02A034).

[59] H. Desimone, A. Bernasconi, S. Beretta, On the application of Dang Van criterion to rolling contact fatigue, Wear 260 (4-5) (2006) 567-572.

[60] M. Ciavarella, H. Maittourman, On the Ekberg, Kabo and Andersson calculation of the Dang Van Highcycle fatigue limit for rolling contact fatigue (letter to the editor), Fatigue Fract. Eng. Mater. Struct. 27 (2004) 523-526.

[61] P.S. van Lieshout, J.H. den Besten, M.L. Kaminski, Validation of the corrected Dang Van multiaxial fatigue criterion applied to turret bearings of FPSO offloading buoys, Ships Offshore Struct. 12 (4) (2017) 521-529.

[62] M. Ciavarella, F. Monno, G. Demelio, On the Dang Van fatigue limit in rolling contact fatigue, Int. J. Fatigue 28 (8) (2006) $852-863$.

[63] S. Beretta, S. Foletti, Propagation of Small Cracks under RCF: A Challenge to Multiaxial Fatigue Criteria, (2012), p. CP2012.

[64] R. Rabb, C. Lönnqvist, J. Kaas, Multiaxial Fatigue Criteria Applied to Medium Speed Diesel Engines, (2010), p. ICMFF9.

[65] M. Cerullo, Application of Dang Van criterion to rolling contact fatigue in wind turbine roller bearings under elastohydrodynamic lubrication conditions, Proc. Inst. Mech. Eng. Part C J. Mech. Eng. Sci. 228 (12) (2014) 2079-2089.

[66] O. Barrera, A. Makradi, M. Abbadi, M. Azaouzi, S. Belouettar, On high-cycle fatigue of 316L stents, Comput. Methods Biomech. Biomed. Engin. 17 (3) (2014) $239-250$.

[67] K.D. Van, H.M. Maitournan, J.F. Flavenot, Fatigue design of notched components by a multiscale approach based on shakedown, Secur. Reliab. Damaged Struct. Defective Mater. (2009) 325.

[68] H. Maitournam, Matériaux et Structures Anélastiques, Ecole Polytechnique Eds, 2017.

[69] "HANSO: Hybrid Algorithm for Non-Smooth Optimization" [Online]. Available: HANSO: Hybrid Algorithm for Non-Smooth Optimization.

[70] HANSO, [Online]. Available http://www.cs.nyu.edu/overton/software/hanso/, Accessed date: 29 August 2017.

[71] J.C. Lagarias, J.A. Reeds, M.H. Wright, P.E. Wright, Convergence properties of the Nelder-Mead simplex method in low dimensions, SIAM J. Optim. 9 (1) (1998) $112-147$.

[72] K. Endo, Y. Miyao, Effects of cycle frequency on the corrosion fatigue strength, Bull. JSME 1 (4) (1958) 374-380.

[73] A. Arredondo, J. Fernández, E. Silveira, J.L. Arana, Corrosion fatigue behavior of mooring chain steel in seawater, ASME 2016 35th International Conference on Ocean, Offshore and Arctic Engineering, American Society of Mechanical Engineers, 2016(V001T01A006-V001T01A006).

[74] CETIM, Dang Van Parameters Determination on Non Corroded and Corrosed Ofshore Chain Steel, (2009). 